\title{
EVALUASI PATI UMBI TALAS (Colocasia esculenta Schott) SEBAGAI BAHAN PENGISI PADA SEDIAAN TABLET PARASETAMOL
}

\author{
Bayu Heris Apriyanto*, Rolan Rusli, Agung Rahmadani \\ Laboratorium Riset dan Pengembangan Kefarmasian "FARMAKA TROPIS" \\ Fakultas Farmasi, Universitas Mulawarman, Samarinda, Kalimantan Timur \\ *Email:bayuilixx@gmail.com
}

\begin{abstract}
ABSTRAK
Umbi talas mengandung kadar pati yang sangat tinggi, sehingga dapat digunakan sebagai bahan pengisi tablet. Penggunaan pati sebagai bahan pengisi umum digunakan dalam formulasi sediaan tablet guna menyempurnakan bentuk tablet. Penelitian ini bertujuan untuk mengetahui evaluasi kualitas granul serta sifat fisik tablet parasetamol dan mengetahui formulasi sediaan tablet parasetamol dengan bahan pengisi pati umbi talas. Penelitian ini diawali dengan isolasi pati talas. Pati talas yang diperoleh, dibuat menjadi 4 formula tablet yaitu F1, F2, F3, dan F4 dengan metode granulasi basah. Konsentrasi pati umbi talas yang digunakan dalam tablet yaitu 8,3\% (F1), 12\% (F2), 15,3\% (F3), dan 18,5\% (F4). Hasil penelitian menunjukkan bahwa keempat formula tablet parasetamol memenuhi persyaratan kualitas granul dan sifat fisik tablet parasetamol. Semakin tinggi konsentrasi pati umbi talas akan menurunkan waktu hancur tablet. Formula F4 merupakan formula terbaik sebagai bahan pengisi tablet parasetamol berdasarkan hasil evaluasi kualitas granul dan evaluasi sifat fisik tablet.
\end{abstract}

Kata Kunci : Pati umbi talas, bahan pengisi, formulasi tablet, parasetamol

\section{PENDAHULUAN}

Hampir semua tablet memerlukan penambahan eksipien untuk berbagai tujuan dengan zat aktif dalam formulasi. Hal ini untuk memperoleh sifat fisik, kimia, mekanik agar memenuhi persyaratan resmi (farmakope) dan persyaratan industri yang dapat diterima serta untuk memudahkan pembuatannya. Dalam formulasi tablet pada umumnya dapat ditambahkan eksipien seperti : pengikat, disintegran, lubrikan, glidan, zat warna, pengisi dan sebagainya, agar memenuhi fungsi farmasetik tersebut (Siregar \& Wikarsa, 2010).

Pati merupakan eksipien serbaguna yang digunakan terutama dalam formulasi sediaan padat oral sebagai bahan pengisi, pengikat dan disintegran. Pati 
dapat diperoleh dari berbagai macam tanaman dan umumnya sangat banyak terdapat pada bagian umbi tanaman dan biji-bijian yang memiliki kandungan karbohidrat yang cukup tinggi (Suhery dkk., 2015).

Penggunaan pati sebagai bahan pengisi dalam tablet umum digunakan dalam formulasi sediaan tablet guna mendapatkan suatu ukuran atau bobot yang sesuai sehingga layak untuk dikempa menjadi tablet. Bahan pengisi biasanya ditambahkan dalam rentang konsentrasi 5-80\% (tergantung jumlah zat aktif dan bobot tablet yang diinginkan). Bahan pengisi yang baik tidak hanya dapat memperbaiki sifat alir dari tablet tetapi dapat juga memperbaiki daya kohesi sehingga mudah untuk dicetak (kompresibel) (Ahmed \& Khan, 2013).

Tanaman talas merupakan salah satu tanaman yang mengandung kadar pati yang tinggi pada bagian umbinya. Bahkan kadar pati pada umbi talas lebih tinggi dibandingkan dengan kadar pati yang terdapat pada umbi singkong. Kadar pati pada umbi talas yaitu sekitar $80 \%$ sedangkan kadar pati pada umbi singkong yaitu sekitar 72,17\% (Rahmawati dkk., 2013). Menurut Chotimah dan Desi (2013), umbi talas mengandung karbohidrat yaitu sekitar 13-29 gram tiap 100 gram umbi talas.

Berdasarkan hal tersebut, maka dilakukan penelitian tentang evaluasi pati umbi talas (Colocasia esculenta Schott) sebagai bahan pengisi pada sediaan tablet parasetamol. Pada penelitian ini diharapkan penggunaan pati umbi talas sebagai bahan pengisi dengan konsentrasi tertentu dapat memperbaiki evaluasi kualitas granul dan sifat fisik tablet parasetamol sekaligus dapat memanfaatkan pati produksi sendiri yang mudah didapat dan relatif murah harganya.

\section{METODE PENELITIAN}

\section{Alat dan Bahan}

Bahan yang digunakan dalam penelitian ini yaitu umbi talas (Colocasia esculenta Schott) yang diambil dari Kelurahan Tanah Merah, Kecamatan Samarinda Utara, Kalimantan Timur, parasetamol BPFI, polivinil pirolidon, magnesium stearat, talkum dan aquadest.

Alat yang digunakan dalam penelitian ini yaitu toples kaca, kain saring, oven, gelas kimia, gelas ukur, batang pengaduk, mortir dan stemper, spatel, loyang, 
penggaris, stopwatch, mikrometer sekrup, timbangan analitik, ayakan no mesh 20 dan 80, alat uji daya alir, mesin pencetak tablet single punch, mesin pengayak dan mechanical tapping device.

\section{PROSEDUR PENELITIAN}

\section{Isolasi Pati Umbi Talas}

Umbi talas dikupas dan ditimbang sebanyak $\pm 7,5 \mathrm{~kg}$. Umbi talas yang sudah dikupas, dicuci sampai bersih. Direndam \pm 2 jam dalam air, kemudian dipotong kecil-kecil dan ditiriskan. Perendaman dilakukan untuk menghilangkan getah pada umbi talas dan kadar kalsium oksalat yang dapat menyebabkan gatal. Kemudian umbi talas yang telah ditiriskan diblender hingga menjadi bubur halus umbi talas. Kemudian disaring dengan menggunakan kain, diperas sampai semua airnya habis. Ampasnya dicampur kembali dengan aquadest kira-kira $1 / 3$ nya, diaduk kemudian diperas lagi hingga airnya habis. Diulangi hingga mendapatkan hasil perasan yang jernih, lalu cairan diendapkan selama 24 jam. Setelah mengendap sempurna, cairan diatasnya yang jernih didekantasi hingga diperoleh endapan pati. Kemudian dikeringkan dalam oven pada suhu $40^{\circ} \mathrm{C}$ selama 24 jam. Pati kering yang berbentuk berupa gumpalan dihaluskan dengan mortir dan stemper kemudian diayak dengan pengayak nomor mesh 80 hingga diperoleh pati berbentuk serbuk (Suhery dkk., 2015).

\section{Pembuatan Granul dan Tablet Parasetamol}

Tablet parasetamol dibuat dengan metode granulasi basah. Dimasukkan parasetamol dan pati umbi talas pada mortir lalu dihomogenkan. Dilarutkan polivinil pirolidon dengan aquadest. Kemudian ditambahkan larutan polivinil pirolidon yang telah dibuat ke dalam mortir, dihomogenkan hingga terbentuk massa yang baik. Dibuat granulasi dengan menggunakan ayakan nomor mesh 20 dan dikeringkan dalam oven pada suhu $40-60^{\circ} \mathrm{C}$. Diayak kembali granul dengan menggunakan ayakan nomor mesh 20 dan dikeringkan kembali dalam oven pada suhu $40-60^{\circ} \mathrm{C}$. Setelah terbentuk granul kering, ditambahkan magnesium starat dan talkum lalu dihomogenkan. Granul kering yang telah siap kemudian dikempa menjadi tablet dengan formula seperti pada tabel 1 . 
Tabel 1. Formula Tablet Parasetamol dengan Pati Umbi Talas Sebagai Bahan Pengisi

\begin{tabular}{lcccc}
\hline \multirow{2}{*}{ Bahan } & \multicolumn{4}{c}{ Berat $\mathbf{( m g )}$} \\
\cline { 2 - 5 } & F1 & F2 & F3 & F4 \\
\hline Parasetamol & 500 & 500 & 500 & 500 \\
Pati Talas & 50 & 75 & 100 & 125 \\
PVP & 35 & 35 & 35 & 35 \\
Talkum & 10 & 10 & 10 & 10 \\
Mg stearat & 5 & 5 & 5 & 5 \\
\hline Bobot tablet (mg) & $\mathbf{6 0 0}$ & $\mathbf{6 2 5}$ & $\mathbf{6 5 0}$ & $\mathbf{6 7 5}$ \\
\hline
\end{tabular}

Keterangan : $\mathrm{F} 1=$ Formula 1 (pati talas $8,3 \%$ ); F2 = Formula 2 (pati talas 12\%); F3 = Formula 3 (pati talas 15,3\%); F4 = Formula 4 (pati talas $18,3 \%)$.

\section{Evaluasi Kualitas Granul}

\section{Uji Sudut Diam}

Penetapan sudut diam dilakukan dengan menggunakan corong yang bagian atas berdiameter $12 \mathrm{~cm}$, diameter bawah $1 \mathrm{~cm}$ dan tinggi $10 \mathrm{~cm}$. Granul dimasukkan ke dalam corong, lalu dialirkan melalui ujung corong dan ditentukan besar sudut diamnya. Persyaratan : Uji dikatakan dapat memenuhi syarat apabila $25^{\circ}>\emptyset<40^{\circ}$ (Rori dkk., 2016). Rumus penetapan sudut diam :

$$
\operatorname{tg} \varnothing=\frac{2 \mathrm{~h}}{D}
$$

Keterangan :

$\emptyset=$ Sudut diam

$\mathrm{D}=$ Diameter tumpukan granul $(\mathrm{cm})$;

$\mathrm{h}=$ Tinggi tumpukan granul $(\mathrm{cm})$

\section{Uji Laju Alir}

Sejumlah tertentu granul dimasukkan kedalam corong yang telah dirangkai, sampai memenuhi $2 / 3$ bagian corong, permukaan granul diratakan, lalu penutup bawah corong dibuka dan secara serentak stopwatch dihidupkan, dibiarkan granul mengalir sampai habis, stopwatch dimatikan jika granul telah habis melewati corong dan dicatat waktu alirnya. Persyaratan : Uji dikatakan memenuhi syarat apabila > 10 gram/detik (Rori dkk., 2016). 


\section{Densitas}

Granul dimasukkan ke dalam gelas ukur hingga volume $100 \mathrm{~mL}$ dan dicatat volume awalnya. Kemudian ditimbang berat granul, lalu dilakukan pengetukan dengan alat mechanical tapping device hingga ketukan ke 500. Setelah itu, dilakukan pengukuran granul yang telah dimampatkan dan diukur sebagai volume mampat, (Lukman dkk., 2013). Dari hasil pengukuran tersebut, dapat dilakukan perhitungan sebagai berikut :

$$
\begin{aligned}
& \text { Bulk density }=\frac{\text { bobot serbuk }(\mathrm{g})}{\text { volume serbuk }(\mathrm{mL})} \\
& \text { Tapped density }=\frac{\text { bobot serbuk }(\mathrm{g})}{\text { volume mampat }(\mathrm{mL})}
\end{aligned}
$$

\section{Indeks Kompresibilitas}

Indeks kompresibilitas merupakan kemampuan granul membentuk massa yang stabil dan utuh ketika diberikan tekanan. Persyaratan : Uji dikatakan memenuhi syarat apabila < 20\% (Lukman dkk., 2013). Indeks kompresibilitas dapat dihitung dengan menggunakan persamaan :

$$
\mathrm{I}=\frac{\text { tapped density }- \text { bulk density }}{\text { bulk density }} \times 100 \%
$$

\section{Evaluasi Sifat Fisik Tablet}

\section{Uji Keseragaman Bobot}

Ditimbang 20 tablet dari masing-masing formula dan dihitung bobot rataratanya. Jika ditimbang satu per satu tidak boleh lebih dari dua tablet yang masingmasing bobotnya menyimpang dari bobot rata-rata yang ditetapkan kolom A dan tidak satupun tablet yang bobotnya menyimpang dari bobot rata-rata yang ditetapkan kolom B sesuai syarat yang tercantum pada Farmakope Indonesia V (Depkes RI, 2013).

\section{Uji Keseragaman Ukuran}

Dipilih 20 tablet dari tiap formula, kemudian diukur tebal dan diameter masing-masing tablet menggunakan alat ukur yaitu mikrometer sekrup. Menurut Farmakope Indonesia V, syarat keseragaman ukuran kecuali dinyatakan lain, 
diameter tablet tidak lebih dari 3 kali dan tidak kurang dari $1 / 3$ kali tebal tablet (Depkes RI, 2013).

\section{Uji Waktu Hancur}

Pengujian dilakukan terhadap 6 tablet. Dimasukkan 1 tablet pada masingmasing tabung dari keranjang. Digunakan air, suhu $37^{\circ} \pm 2^{\circ} \mathrm{C}$ sebagai media. Pada akhir batas waktu seperti yang tertera pada monografi, angkat keranjang dan amati keenam tablet. Semua tablet harus hancur sempurna. Bila 1 atau 2 tablet tidak hancur sempurna ulangi pengujian dengan 12 tablet lainnya, tidak kurang dari 16 tablet dari 18 tablet yang diuji harus hancur sempurna. Persyaratan : Waktu hancur tablet yaitu < 15 menit untuk tablet tidak bersalut (Depkes RI, 2013).

\section{HASIL DAN PEMBAHASAN}

\section{Pemeriksaan Organoleptis Pati Umbi Talas}

Tabel 2. Hasil Pemeriksaan Organoleptis Umbi Talas

\begin{tabular}{cccc}
\hline Bau & Rasa & Warna & Bentuk \\
\hline Tidak berbau & $\begin{array}{r}\text { Tidak } \\
\text { berasa }\end{array}$ & Putih & Serbuk halus \\
\hline
\end{tabular}

Dari hasil pemeriksaan pati umbi talas didapatkan hasil bahwa pati umbi talas berbentuk serbuk, dengan warna putih dan pati umbi talas yang dihasilkan tidak berbau serta tidak berasa. Standar organoleptis untuk pati adalah serbuk halus, tidak berasa, tidak berbau dan berwarna putih. Berdasarkan hasil penelitian, dapat dikatakan bahwa pati umbi talas telah memenuhi standar pada pemeriksaan organoleptis sebagai eksipien pada formulasi tablet.

\section{Hasil Evaluasi Kualitas Granul}

\section{Hasil Uji Sudut Diam}

Berdasarkan hasil uji sudut diam granul pada tabel 3, diketahui bahwa keempat formula memiliki nilai sudut diam yang baik dimana syarat untuk nilai sudut diam yaitu $25^{\circ} \geq \alpha \leq 40^{\circ}$ (Rori dkk., 2016). Pada F4 (formula 4) memiliki sudut diam yang paling kecil jika dibandingkan dengan F3 (formula 3) hingga F1 (formula 1). Dimana dalam hal ini semakin kecil sudut diam maka sifat aliran granul akan semakin baik dan semakin baik sifat aliran granul maka granul akan semakin 
mudah untuk dikempa dalam pembuatan tablet. Sudut diam merupakan sudut maksimum yang mungkin terjadi antara permukaan gundukan serbuk dan bidang horizontal, untuk mengukur gaya gesekan pada serbuk tabur (Sinko, 2011).

Tabel 3. Hasil Pengujian Sudut Diam Granul

\begin{tabular}{|c|c|c|c|c|c|}
\hline \multirow{2}{*}{ Formula } & \multicolumn{4}{|c|}{ Sudut Diam $\left(^{\circ}\right)$} & \multirow{2}{*}{ Syarat } \\
\hline & 1 & 2 & 3 & Rata-Rata \pm SD & \\
\hline F1 & 25,31 & 27,06 & 28,23 & $26,86 \pm 1,47$ & \\
\hline $\mathrm{F} 2$ & 27,34 & 26,54 & 25,52 & $26,47 \pm 0,91$ & \\
\hline F3 & 27,42 & 26,33 & 24,22 & $25,99 \pm 7,84$ & (Rori dkk., 2016) \\
\hline $\mathrm{F} 4$ & 27,65 & 24,75 & 25,03 & $25,81 \pm 1,59$ & \\
\hline
\end{tabular}

\section{Hasil Uji Densitas}

Tabel 4. Hasil Uji Densitas

\begin{tabular}{ccccc}
\hline \multirow{2}{*}{ Densitas } & \multicolumn{4}{c}{ Formula } \\
\cline { 2 - 5 } & $\mathrm{F} 1$ & $\mathrm{~F} 2$ & $\mathrm{~F} 3$ & $\mathrm{~F} 4$ \\
\hline \multirow{2}{*}{ Bulk density } & 0,452 & 0,445 & 0,458 & 0,446 \\
$(\mathrm{~g} / \mathrm{mL})$ & 0,456 & 0,448 & 0,457 & 0,458 \\
& 0,455 & 0,456 & 0,454 & 0,456 \\
\hline Rata-Rata \pm SD & $0,454 \pm 0,002$ & $0,449 \pm 0,005$ & $0,456 \pm 0,002$ & $0,453 \pm 0,006$ \\
\hline \multirow{2}{*}{ Tap density } & 0,481 & 0,469 & 0,493 & 0,496 \\
$(\mathrm{~g} / \mathrm{mL})$ & 0,480 & 0,472 & 0,486 & 0,503 \\
& 0,479 & 0,480 & 0,488 & 0,512 \\
\hline Rata-Rata \pm SD & $0,480 \pm 0,001$ & $0,465 \pm 0,005$ & $0,489 \pm 0,003$ & $0,504 \pm 0,008$ \\
\hline
\end{tabular}

Pengukuran densitas meliputi bulk density berpengaruh terhadap laju alir serbuk, dimana semakin besar bulk density maka laju alir akan semakin baik (Rowe dkk., 2009). Nilai densitas berbanding lurus dengan massa partikel, semakin besar ukuran partikel maka akan meningkatkan massa sehingga nilai bulk density menjadi lebih besar. Ketika ukuran partikel semakin besar maka laju alir akan meningkat dikarenakan berkurangnya gaya kohesi antar partikel.

Sedangkan pengukuran densitas meliputi tapped density berpengaruh terhadap nilai kompresibilitas, dimana proses pembuatan tablet salah satunya terdiri dari proses pengempaan serbuk atau kompresibilitas, yang bertujuan untuk mengubah massa serbuk yang tidak berikatan menjadi suatu bentuk kesatuan sediaan padat tunggal. 
Berdasarkan hasil uji densitas pada tabel 4, pada formula 3 (F3) memiliki nilai bulk density terbesar yaitu $0,456 \mathrm{~g} / \mathrm{mL}$ sedangkan untuk nilai tap density terbesar yaitu pada formula 4 (F4) dengan nilai tap density $0,504 \mathrm{~g} / \mathrm{mL}$. Dalam hal ini, formula 3 (F3) memiliki ukuran partikel yang lebih besar dibandingkan dengan F1, F2 dan F4. Ukuran partikel yang besar akan meningkatkan laju alir dikarenakan gaya kohesi antar partikel berkurang. Sedangkan untuk formula 4 (F4) akan memiliki nilai indeks kompresibilitas yang tinggi.

\section{Hasil Nilai Indeks Kompresibilitas}

Tabel 5. Hasil Nilai Indeks Kompresibilitas

\begin{tabular}{|c|c|c|c|c|c|}
\hline \multirow{2}{*}{ Formula } & \multicolumn{4}{|c|}{ Indeks Kompresibilitas (\%) } & \multirow{2}{*}{ Syarat } \\
\hline & 1 & 2 & 3 & Rata-Rata \pm SD & \\
\hline F1 & 6,41 & 5,26 & 5,27 & $5,65 \pm 0,66$ & \multirow{4}{*}{$\begin{array}{l}5-12 \% \\
\text { (Lukman dkk., } \\
\text { 2013). }\end{array}$} \\
\hline $\mathrm{F} 2$ & 5,39 & 5,35 & 5,26 & $5,33 \pm 0,06$ & \\
\hline F3 & 7,64 & 6,34 & 7,48 & $7,15 \pm 0,71$ & \\
\hline F4 & 11,21 & 9,82 & 12,28 & $11,10 \pm 1,23$ & \\
\hline
\end{tabular}

Berdasarkan hasil nilai indeks kompresibilitas pada tabel 5, keempat formula memiliki laju alir yang baik. Sehingga dapat memudahkan dalam proses pengempaan tablet. Menurut Gad (2008) nilai indeks kompresibilitas sebesar 5$12 \%$ menunjukkan sifat aliran sangat mudah mengalir. Proses pembuatan tablet salah satunya terdiri dari proses pengempaan serbuk atau kompresibilitas, yang bertujuan untuk mengubah massa serbuk yang tidak berikatan menjadi suatu bentuk kesatuan sediaan padat tunggal. Hubungan indeks kompresibilitas dalam pemanfaatan formulasi tablet adalah untuk memprediksi sifat alir, sehingga jika nilai indeks kompresibilitas besar maka laju alir yang dihasilkan kurang baik dimana hal ini berpengaruh terhadap keseragaman bobot dari tablet yang dikempa, karena pengaruh laju alir serbuk yang keluar dari hopper pada mesin pencetak tablet.

\section{Hasil Uji Laju Alir}

Hasil uji laju alir granul pada tabel 6, formula 4 (F4) memiliki kecepatan alir lebih besar dibandingkan formula 3 (F3) hingga Formula 1 (F1). Hal ini sesuai dengan pernyataan Lukman dkk. (2013) yang menjelaskan bahwa semakin besar kecepatan alir maka sudut diamnya akan semakin kecil. Kecepatan alir yang besar 
dapat membuat granul mengalir bebas (free flowing) dan membentuk sudut diam yang kecil. Semakin besar kecepatan alir granul maka akan membentuk kerucut yang semakin datar. Semakin datar kerucut yang terbentuk maka sudut diam yang terbentuk semakin kecil. Hal tersebut membuat granul lebih cepat untuk mengalir ke die pada alat pencetak tablet sehingga proses pengempaan tablet akan berjalan dengan baik. Penambahan Magnesium stearat sebagai glidan dan talkum sebagai lubrikan dapat membantu mengurangi gaya kohesivitas sehingga memperbaiki kecepatan alir dan bentuk granul yang tidak seragam. Granul dikatakan mengalir dengan baik (free flowing) jika kecepatan alir granul lebih besar dari 10 g/detik (Rori dkk., 2016)

Tabel 6. Hasil Pengujian Laju Alir

\begin{tabular}{cccccl}
\hline \multirow{2}{*}{ Formula } & \multicolumn{4}{c}{ Kecepatan alir (g/detik) } & \multirow{2}{*}{ Syarat } \\
\cline { 2 - 5 } & 1 & 2 & 3 & Rata-Rata \pm SD & \\
\hline F1 & 11,62 & 11,62 & 11,36 & $11,53 \pm 0,15$ & \multirow{2}{*}{ > 10 g/detik } \\
F2 & 11,36 & 11,62 & 11,90 & $11,62 \pm 0,27$ & (Rori dkk., \\
F3 & 12,34 & 12,04 & 12,04 & $12,14 \pm 0,17$ & 2016) \\
F4 & 14,49 & 12,82 & 13,33 & $13,54 \pm 0,85$ & \\
\hline
\end{tabular}

\section{Hasil Sifat Fisik Tablet}

\section{Keseragaman Bobot}

Uji keseragaman bobot dapat dipengaruhi oleh distribusi ukuran rata-rata granul dan waktu alir granul, sebab distribusi ukuran granul yang tidak normal akan menyebabkan granul mengalir kurang bebas dan menyebabkan kecenderungan partikel yang berbeda selama mengalir melalui hopper pada proses pencetakan tablet.

Berdasarkan hasil yang diperoleh dari uji keseragaman bobot pada tabel 7 menunjukkan bahwa sesuai dengan persyaratan untuk tablet dengan bobot rata-rata lebih dari $300 \mathrm{mg}$, tidak ada tablet yang bobotnya menyimpang lebih dari 5\% dari bobot rata-rata dan tidak satupun tablet yang bobotnya menyimpang lebih dari $10 \%$ dari bobot rata-rata. Hasil tersebut menunjukkan bahwa tablet formula 1 dan formula 2 memenuhi persyaratan keseragaman bobot tablet yang ditetapkan Farmakope Indonesia V. 
Tabel 7. Hasil Sifat Fisik Tablet

\begin{tabular}{|c|c|c|c|c|c|c|}
\hline \multirow{2}{*}{ No } & \multirow{2}{*}{ Pengujian } & \multicolumn{4}{|c|}{ Hasil (Rata-Rata \pm SD) } & \multirow{2}{*}{ Syarat } \\
\hline & & F1 & $\mathrm{F} 2$ & F3 & F4 & \\
\hline \multirow[t]{2}{*}{1} & Keseragaman & 592,75 & 623,05 & 643,25 & 664,95 & \multirow{2}{*}{$\begin{array}{l}<10 \% \text { bobot tablet } \\
\text { (Depkes RI, 2013) }\end{array}$} \\
\hline & Bobot (mg) & $\pm 13,19$ & $\pm 17,02$ & $\pm 16,08$ & $\pm 14,74$ & \\
\hline \multirow[t]{5}{*}{2} & Keseragaman & & & & & \multirow{5}{*}{$\begin{array}{l}3 \times \text { Tebal tablet } \geq \mathrm{D} \\
\geq 11 / 3 \mathrm{X} \text { Tebal tablet } \\
(\text { Depkes RI, 2013) }\end{array}$} \\
\hline & Ukuran $(\mathrm{mm})$ : & & & & & \\
\hline & - Diameter & 12,041 & 12,129 & 12,038 & 12,173 & \\
\hline & & $\pm 0,014$ & $\pm 0,062$ & $\pm 0,015$ & $\pm 0,023$ & \\
\hline & - Ketebalan & $\begin{array}{r}6,107 \\
\pm 0,057\end{array}$ & $\begin{array}{r}6,119 \\
\pm 0,137\end{array}$ & $\begin{array}{c}6,267 \\
\pm 0,151\end{array}$ & $\begin{array}{c}6,305 \\
\pm 0,136\end{array}$ & \\
\hline 3 & $\begin{array}{l}\text { Waktu Hancur } \\
\text { (menit) }\end{array}$ & $\begin{array}{c}1,40 \\
\pm 0,061\end{array}$ & $\begin{array}{c}1,47 \\
\pm 0,065 \\
\end{array}$ & $\begin{array}{c}2,37 \\
\pm 0,185 \\
\end{array}$ & $\begin{array}{c}4,33 \\
\pm 0,201 \\
\end{array}$ & $\begin{array}{c}<15 \text { menit } \\
(\text { Depkes RI, 2013) }\end{array}$ \\
\hline
\end{tabular}

\section{Keseragaman Ukuran}

Ketebalan tablet dipengaruhi oleh beberapa hal yaitu tekanan pada saat mencetak tablet, jumlah massa yang diisikan pada ruang cetak tablet dan kerapatan massa tablet yang dicetak sedangkan diameter tablet dapat dipengaruhi oleh ukuran ruang cetak tablet (Rori dkk., 2016). Dari hasil yang tertera pada tabel 7, menunjukkan bahwa keempat formula memenuhi syarat keseragaman ukuran tablet yaitu diameter tablet tidak lebih dari 3 kali tebal tablet dan tidak kurang dari $1 \frac{1}{3}$ kali tebal tablet.

\section{Waktu Hancur}

Hasil yang didapat dari uji waktu hancur tablet, keempat formula telah memenuhi syarat waktu hancur untuk tablet tidak bersalut menurut Farmakope Indonesia V yaitu tidak lebih dari 15 menit. Hasil uji waktu hancur tablet bisa dilihat pada tabel 7 bahwa semakin tinggi konsentrasi pati yang digunakan maka semakin lama tablet untuk hancur. Dalam hal ini, penggunaan pati dapat mempercepat penyerapan air sehingga akan memungkinkan untuk dapat menarik air melalui kerja kapiler (Rori dkk., 2016).

\section{KESIMPULAN}

1. Pati umbi talas (Colocasia esculenta Schoot) dapat digunakan sebagai pengisi (diluent) dalam sediaan tablet parasetamol dengan rentang konsentrasi 8,3\% $-18,5 \%$. 
2. Dari hasil evaluasi kualitas granul dan sifat fisik tablet, keempat formula yaitu F1, F2, F3 dan F4 telah memenuhi persyaratan berdasarkan Farmakope Indonesia dan formula F4 merupakan formula terbaik sebagai bahan pengisi berdasarkan hasil evaluasi kualitas granul dan sifat fisik tablet.

\section{DAFTAR PUSTAKA}

Ahmed, A. dan Khan, F. 2013. Extraction of Starch from Taro (Colocasia esculenta) and Evaluating it and further using Taro Starch as Disintegrating Agent in Tablet Formulation with Over All Evaluation. Inventi Rapid: Novel Excipients. Nomor 2, Volume 1, Halaman : 1-5.

Chotimah, S. dan Desi, T. F. 2013. Reduksi Kalsium Oksalat dengan Perebusan Menggunakan Larutan $\mathrm{NaCl}$ dan Penepungan untuk Meningkatkan Kualitas Sente (Alocasia macrorrhiza) sebagai Bahan Pangan. Jurnal Teknologi Kimia dan Industri. Nomor 2, Volume 2, Halaman : 76-83.

Depkes RI, 2013. Farmakope Indonesia Edisi V. Departemen Kesehatan Direktorat Jenderal Pengawasan Obat dan Makanan: Jakarta.

Gad, Shayne C. 2008. Pharmaceutical Manufacturing Handbook Production and Processes. A John Wiley \& Sons Inc Hoboken: New Jersey.

Lukman, Anita dan Deni Anggraini. 2013. Pembuatan dan Uji Sifat Fisikokimia Pati Beras Ketan Kampar yang Dipragelatinasi. Jurnal Penelitian Farmasi Indonesia. Nomor 2, Volume 1, Halaman : 67-71.

Rahmawati, W., Kusumastuti, A., Yovita dan Aryanti, N. 2012. Karakterisasi Sifat dari Pati Umbi

Talas (Colocasia esculenta (L.) Schoot) Sebagai Alternatif Sumber Pati Industri Di Indonesia. Jurnal Teknologi Kimia dan Industri. Nomor 1, Volume 1, Halaman : 347-351.

Rori, M. W., Yamlean, P.V. dan Sudewi, Sri. 2016. Formulasi dan Evaluasi Sediaan Tablet Ekstrak Daun Gedi Hijau (Albemoschus manihot) Dengan Metode Granulasi Basah. Jurnal Ilmiah Farmasi-UNSRAT. Nomor 2, Volume 5, Halaman : 243-250.

Rowe, Raymond, C., Paul, J. S. dan Marian, E. Q. 2009. Handbook of Pharmaceutical Excipients Sixth Edition. Pharmaceutical Press and American Pharmacists Association: USA.

Sinko, Patrick J. 2011. Farmasi Fisika dan Ilmu Farmasetika Martin. EGC: Jakarta. Siregar, C. J. P. dan Wikarsa, S. 2010. Teknologi Farmasi Sediaan Tablet DasarDasar Praktis. Buku Kedokteran EGC : Jakarta.

Suhery, N. W., Anggraini, Dewi dan Endri, Novtafia. 2015. Pembuatan dan Evaluasi Pati Umbi Talas (Colocasia esculenta Schott) Termodifikasi dengan Bakteri Asam Laktat (Lactobacillus sp). Jurnal Sains Farmasi \& Klinis. Nomor 2, Volume 1, Halaman : 207-214. 